\title{
A Study to Assess the Neurocognitive Profile of Patients with OCD and Depression
}

\author{
Musuku Srikanth Reddy \\ Assistant Professor, Department of Psychiatry, Kamineni Medical College, Narketpally, Telangana, India.
}

\section{Abstract}

Background: The present study was conducted to assess the neurocognitive profile of patients with OCD and depression. Subjects \& Methods: It comprised of patients of OCD (42) and depression (42) of both genders. An equal number of healthy control was also recruited. VAIS and performance tests of intelligence (BSS) were recorded. Results: Group I had 22 males and 20 females, group II had 18 males and 24 females and group III had 21 males and 21 females. The value for VAIS and performance tests of intelligence (BSS) parameters such as information were 94.2, 96.4 and 98.3 in all groups respectively, digit span was 103.4, 102.5 and 105.6 in all groups respectively, arithmetic was $95.8,96.2$ and 8.4 in all groups respectively, comprehension was 102.4, 104.5 and 107.3 in all groups respectively, verbal quotient was 105.2 in group I, 103.6 in group II and 10.6.7 in group III respectively. Block design was 9.12, 10.2 and 10.4 in all groups respectively, pass along test was 9.4, 9.8 and 10.2 in all groups respectively and the performance quotient was 102.2, 103.5 and 10.5 .7 in all groups respectively. The difference was non-significant $(\mathrm{P}>0.05)$. Conclusion: Neuropsychological/cognitive parameters in patients with OCD, depression and healthy control were comparables.

Keywords: Depression, OCD, VAIS.

Corresponding Author: Musuku Srikanth Reddy, Assistant Professor, Department of Psychiatry, Kamineni Medical College, Narketpally, Telangana, India.

E-mail: jgdjmrjsmj@gmail.com

Received: 20 September 2020

Revised: 16 November 2020

Accepted: 27 November 2020

Published: 31 December 2020

\section{Introduction}

Obsessive-Compulsive Disorder (OCD) is a highly debilitating neuropsychiatric condition with an estimated lifetime prevalence of 2-3 percent. However unlike other neuropsychiatric conditions; relatively little is understood about the etiology, neural substrate and cognitive profile of OCD. Until recently OCD was described as a neurotic illness or a manifestation of psychodynamic conflict. ${ }^{[1]}$

According to the World Health Organization, OCD is the sixth most disabling psychiatric disorder. ${ }^{[2]}$ In the absence of effective treatment, obsessive-compulsive disorder (OCD) tends to have a chronic course and is associated with poor quality of life and severe impairment of functioning in various domains of life including work, relationships, social life, health, and home responsibilities. ${ }^{[3]}$ Current approaches to OCD suggest that neurobiological abnormalities are involved in its pathogenesis. Moreover renewed interest in demonstrating neuropsychological deficits in OCD has been encouraged by brain imaging studies suggesting a putative front-striatial biological basis for the condition. ${ }^{[4]}$
Several studies suggested that the performances of OCD patients on executive functioning tasks were similar to those of healthy controls, whereas others have reported poorer performance for OCD patients on the same measures. ${ }^{[5]}$ The decrement in cognition has been attributed to reduced motivation, attenuated attentional capacity, impaired concentration, intrusive thought and slowness. Melancholic depression shows more cognitive deficit in comparison with non-melancholic depression. ${ }^{[6]}$ The present study was conducted to assess the neurocognitive profile of patients with OCD and depression.

\section{Subjects and Methods}

The present study was conducted in the Department of Psychiatry. It comprised of patients of OCD (42) and depression (42) of both genders. An equal number of healthy control was also recruited. The study was approved by the institutional ethical committee. All were informed regarding the study and their consent was obtained. Diagnosis of OCD and depression was confirmed with the help of ICD-10 by an expert psychiatrist. 
Data such as name, age, gender etc. was recorded. They were divided into 3 groups. Group I had OCD patients, group II had depression patients and group II had control. Education, occupation, marital status, monthly income, VAIS and performance tests of intelligence (BSS) was recorded. Results were tabulated and subjected to statistical analysis. A p-value of less than 0.05 was considered significant.

\section{Results}

Table 1: Distribution of patients

\begin{tabular}{llll}
\hline Groups & Group I & Group II & Group III \\
Status & OCD & Depression & Control \\
M: F & $22: 20$ & $18: 24$ & $21: 21$ \\
\hline
\end{tabular}

[Table 1] shows that group I had 22 males and 20 females, group II had 18 males and 24 females and group III had 21 males and 21 females.

[Table $2 \&$ Figure 1] shows that the value for VAIS and performance tests of intelligence (BSS) parameters such as information was $94.2,96.4$ and 98.3 in all groups respectively, digit span was 103.4, 102.5 and 105.6 in all groups respectively, arithmetic was $95.8,96.2$ and 98.4 in all groups respectively, comprehension was 102.4, 104.5 and 107.3 in all groups respectively, verbal quotient was 105.2 in group I, 103.6 in group II and 10.6.7 in group III respectively. Block design was 9.12, 10.2 and 10.4 in all groups respectively, pass along test was 9.4, 9.8and 10.2 in all groups respectively and performance quotient was 102.2, 103.5 and 10.5.7 in all groups respectively. The difference was non-significant $(\mathrm{P}>0.05)$.

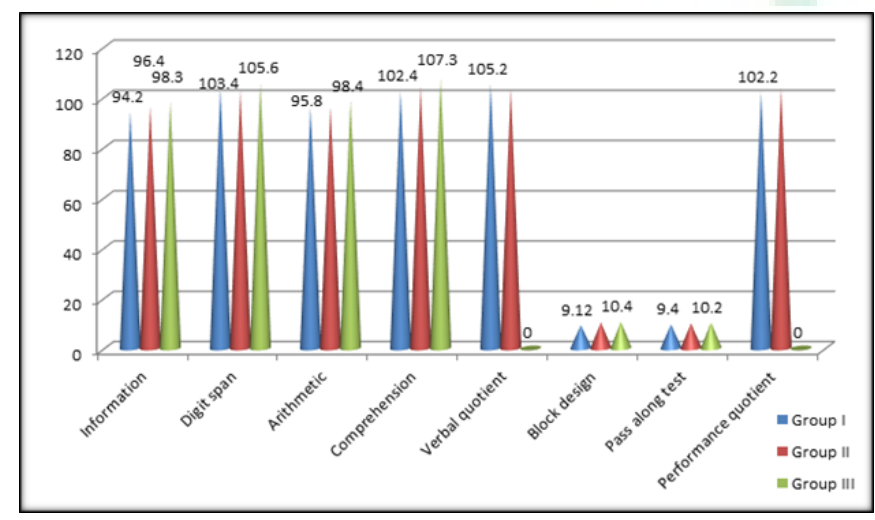

Figure 1: Comparison of VAIS and performance tests of Intelligence (BSS)

\section{Discussion}

OCD causes considerable disability. While the 1990 and 2000 Global Burden of Disease (GBD) studies included three specific anxiety disorders: post-traumatic stress disorder (PTSD), panic disorder (PD), and OCD, due to the high degree of comorbidity across anxiety disorders, the 2010 GBD assessed the burden of all anxiety disorders but chose not to provide estimates for specific anxiety disorders. ${ }^{[7]}$ Studies on neuropsychological functioning in OCD have documented deficits in several cognitive domains, particularly visuospatial abilities, executive functioning, motor speed and memory. ${ }^{[8]}$ Clinical observations have also suggested the presence of fundamental processing deficits but abnormalities in several other cognitive domains including executive functions, memory, and visuospatial skills are inconsistent. ${ }^{[9]}$ The present study was conducted to assess the neurocognitive profile of patients with OCD and depression.

In the present study, group I had 42 patients with OCD, group II had 42 patients with depression and group III had healthy control. Group I had 22 males and 20 females, group II had 18 males and 24 females and group III had 21 males and 21 females. Kumar et al, ${ }^{[10]}$ investigated the neurocognitive profile of patients with OCD and depression disorder in the remission phase and their comparison with healthy controls. Results do not provide evidence for a localized neuropsychological/cognitive impairment in patients with OCD in the remission phase in comparison to healthy controls. However patients of unipolar depression in the remission phase exhibit statistically significant differences in cognitive deficits within the domain of mental flexibility (executive control over actions) in comparison to healthy controls.

We found that value for VAIS and performance tests of intelligence (BSS) parameters such as information was 94.2, 96.4 and 98.3 in all groups respectively, digit span was 103.4, 102.5 and 105.6 in all groups respectively, arithmetic was 95.8, 96.2 and 98.4 in all groups respectively, comprehension was $102.4,104.5$ and 107.3 in all groups respectively, verbal quotient was 105.2 in group I, 103.6 in group II and 10.6.7 in group III respectively. Block design was 9.12, 10.2 and 10.4 in all groups respectively, pass along test was 9.4, 9.8and 10.2 in all groups respectively and performance quotient was 102.2, 103.5 and 10.5.7 in all groups respectively. The difference was non-significant $(\mathrm{P}>0.05)$.

Kohli et al, ${ }^{[11]}$ included 20 clinically stable outpatients with an ICD-10 diagnosis of OCD and an equal number of normal controls matched for age, education, gender and handedness were studied using a battery of neuropsychological tests. The tests consisted of verbal and performance tests of intelligence, memory, perceptual-motor functions, set test and Wisconsin Card Sorting Test (WCST). On perceptual-motor functions, 
Table 2: Comparison of VAIS and performance tests of Intelligence (BSS)

\begin{tabular}{lllll}
\hline Parameters & Group I & Group II & Group III & P-value \\
\hline Information & 94.2 & 96.4 & 98.3 & 0.12 \\
\hline Digit span & 103.4 & 102.5 & 105.6 & 0.14 \\
\hline Arithmetic & 95.8 & 96.2 & 98.4 & 0.23 \\
\hline Comprehension & 102.4 & 104.5 & 107.3 & 0.16 \\
\hline Verbal quotient & 105.2 & 103.6 & 10.6 .7 & 0.65 \\
\hline Block design & 9.12 & 10.2 & 10.4 & 0.17 \\
\hline Pass along test & 9.4 & 9.8 & 10.2 & 0.11 \\
\hline Performance quotient & 102.2 & 103.5 & 10.5 .7 & 0.82 \\
\hline
\end{tabular}

verbal fluency, executive functions (WCST), intelligence and memory patients with OCD did not show impairments comparable to healthy controls. An attempt to correlate the test findings with the duration of illness, stability of illness and the average drug dose was made and it was found that there was no correlation between the two. The present study does not provide evidence for a localized neuropsychological/cognitive impairment in OCD in cases that are stable for at least three months.

Sharma et al, ${ }^{[12]}$ focused on patient-reported outcome measures (PROMs) that evaluated three broad outcome domains: functioning, health-related quality of life (HRQoL), and OCDrelated symptoms. A total of 155 unique articles and 22 PROMs were included. An examination of the PROs revealed that OCD patients tend to suffer from a significant functional disability and report lower HRQoL than controls. OCD patients report greater symptom severity than patients with other mental disorders and evidence indicates that PROMs are sensitive to change and maybe even better than clinicianrated measures at predicting treatment outcomes. Nonetheless, it should be noted that the measures reviewed lacked patient input in their development.

The shortcoming of the study is the small sample size.

\section{Conclusion}

The authors found that neuropsychological/cognitive parameters in patients with OCD, depression and healthy control were comparables.

\section{References}

1. Baxter LR, Schwartz JM, Bergman KS, Szuba MP, Guze BH, Mazziotta JC. Caudate glucose metabolic rate changes with both drug and behavior therapy for obsessive-compulsive disorder. Arch Gen Psychiatry. 1992;49(9):681-690. Available from: https://doi.org/10.1001/archpsyc.1992.01820090009002.
2. Westenberg HGM, Fineberg NA, Denys D. Neurobiology of Obsessive-Compulsive Disorder: Serotonin and Beyond. CNS Spectr. 2007;12(S3):14-27. Available from: https://dx.doi.org/ 10.1017/s1092852900002479.

3. Aydýn PÇ, Öyekçin G, D. Cognitive functions in patients with obsessive compulsive disorder. Turk J Psychiatry. 2013;24:266-313. Available from: https://doi.org/10.1017/ s0033291713001803.

4. Savage CR, Baer L, Keuthen NJ, Brown HD, Rauch SL, Jenike MA. Organizational strategies mediate nonverbal memory impairment in obsessive-compulsive disorder. Biol Psychiatry. 1999;45(7):905-916. Available from: https://dx.doi.org/10. 1016/s0006-3223(98)00278-9.

5. Moritz S, Birkner C, Kloss M, Jacobsen D, Fricke S, Böthern A, et al. Impact of comorbid depressive symptoms on neuropsychological performance in obsessive-compulsive disorder. J Abnorm Psychol. 2001;110(4):653-657. Available from: https://dx.doi.org/10.1037/0021-843x.110.4.653.

6. Austin MP, Mitchell P, Goodwin GM. Cognitive deficits in depression: Possible implications for functional neuropathology. Br J Psychiatry. 2001;178(3):200-206. Available from: https://dx.doi.org/10.1192/bjp.178.3.200.

7. Muller WR. Psychological deficit in depression. Psychol Bull. 1975;82:238-60. Available from: https://doi.org/10.1037/ h0076367.

8. Austin MP, Ross M, Murray C, O'Caŕroll RE, Ebmeier KP, Goodwin GM. Cognitive function in major depression. J Affect Disord. 1992;25(1):21-29. Available from: https://dx.doi.org/ 10.1016/0165-0327(92)90089-o.

9. Chandra S, Agarwal AK. Memory in depression. Indian J Psychiatry. 1982;24(4):338-383.

10. Kumar R, Dhariwal R, Verma KK, Acharya J. A Study to Assess the Neurocognitive Profile of Patients with OCD \& Depression (In Remission Phase). J Adv Med Dent Scie Res. 2019;7(9):166-170.

11. Kohli A, Rana DK, Gupta N, Kulhara P. Neuropsychological Assessment in Obsessive-Compulsive Disorder. Indian J Psychol Med. 2015;37:205-211. Available from: https://dx. doi.org/10.4103/0253-7176.155624.

12. Sharma I, Singh P, Agnihotri SS. John S, Kuruvilla K. Cognitive dysfunction in Depression. Indian J Psychiatry. 1984;26:30-33. 
Copyright: (C) the author(s), 2020. It is an open-access article distributed under the terms of the Creative Commons Attribution License (CC BY 4.0), which permits authors to retain ownership of the copyright for their content, and allow anyone to download, reuse, reprint, modify, distribute and/or copy the content as long as the original authors and source are cited.

How to cite this article: Reddy MS. A Study to Assess the Neurocognitive Profile of Patients with OCD and Depression. Asian J. Med. Res. 2020;9(4):5-8.

DOI: dx.doi.org/10.47009/ajmr.2020.9.4.PY2

Source of Support: Nil, Conflict of Interest: None declared. 